\title{
THREE CIRCLES MODEL REVITALISASI LEMBAGA PENGELOLA ZAKAT
}

\author{
Yulinartati \\ Dosen Universitas Muhammadiyah (UNMUH) Jember \\ yulinartati@yaboo.co.id \\ Ahmad Roziq \\ Dosen Universitas Jember (UNEJ) \\ abmadroziq@yahoo.com \\ Lely Ana Ferawati Ekaningsih \\ Dosen Sekolah Tinggi Agama Islam Darussalam (STAIDA) Banyuwangi \\ lelyningsib@ymail.com
}

\begin{abstract}
This study aims to identify and analyze: (a) potential sources of zakat, infak, and sedekah in Jember Regency, (b) systems and methods of fundraising, management, and distribution conducted by institutions of zakat, infak, and sedekah, (c) accountability of zakat, infak, and sedekab institutions, (d) the usefulness of such funds to the recipient of zakat, infak, and sedekah, and (e) create a model of revitalization of management of zakat, infak, and sadaqab institutions. Type of research is survey research by applying descriptive qualitative method. The results of this study found that management needs to revitalize institutions of zakat, infak, and sedekah as described in the Three Circles Model.
\end{abstract}

Key words: Zakat, Infak, Sedekah, Zakat Management Institution

\begin{abstract}
Abstrak
Penelitian ini bertujuan untuk mengetabui dan menganalisis; (a) potensi sumber dana zakat, infak, dan sedekah di Kabupaten Jember;(b) sistem dan metode penggalangan, pengelolaan, dan pendistribusian yang dilakukan oleb lembaga pengelola zakat, infak, dan sedekah, (c) akuntabilitas lembaga pengelola zakat, infak, dan sedekah (d) kebermanfaatan dana tersebut bagi penerima zakat, infak, dan sedekah, dan (e) membuat model revitalisasi pengelolaan Lembaga Pengelola Zakat. Penelitian ini benrbentuk surve dengan analisis deskriptif kualitatif. Hasil penelitian ini menemukan bahwa lembaga pengelola zakat perlu melakukan revitalisasi seperti yang dijelaskan dalam Model Tiga Lingkaran (Three Circles Model).
\end{abstract}

Kata kunci: Zakat, Infak, Sedekah, Lembaga Pengelola Zakat, Model Tiga Lingkaran 


\section{Pendahuluan}

Zakat, infak, dan sedekah merupakan salah satu bentuk kepedulian sosial. Kelemahan pengelolaan zakat, infak, dan sedekah selama ini ditunjukkan dengan ketidakmampuan lembaga pengelola menjelaskan berapa orang yang mengeluarkan zakat, berapa nilai tiaptiap kelompok zakat, berapa nilai sedekah bulanan, siapa penerima zakat, apakah zakat telah dihitung dengan benar, dan lain hal berkaitan dengan distribusi zakat, infak dan sedekah.

Organisasi pengelola zakat (OPZ) dituntut mampu untuk menjamin transparansi dan akuntabilitas organisasi. Dengan disahkannya Undang-Undang Nomor 23 Tahun 2011 Tentang Pengelolaan Zakat yang menggantikan Undang-Undang Nomor 38 Tahun 1999, diharapkan dapat memberikan kepastian dan tanggung jawab baru kepada pemerintah dalam mengelola badan amil zakat (BAZNAS) dan mampu mengkoordinasikan kepentingan stake holders. Namun, pada kenyataannya belum semua OPZ siap menghadapi UUKIP dan Undang-Undang Nomor 23 Tahun 2011, khususnya dalam menyediakan transparansi publik.

Dari uraian latar belakang tersebut di atas, maka permasalah dalam penelitian ini adalah: Bagaimanakah potensi sumber dana zakat, infak, dan sedekah di Kabupaten Jember? Bagaimakah sistem dan metode penggalangan, pengelolaan, dan pendistribusian yang dilakukan oleh lembaga-lembaga pengelola zakat, infak, dan sedekah? Apakah akuntabilitas lembaga pengelola zakat, infak, dan sedekah telah cukup memadai? Bagaimanakan kebermanfaatan dana tersebut bagi penerima zakat, infak, dan sedekah? Bagaimanakah model revitalisasi Lembaga Pengelola Zakat?

\section{Pengumpulan, Distribusi Dan Pendayagunaaan Zakat}

Ismail (2009:2) memberikan pedoman tentang pola pengumpulan, distribusi dan pendayagunaaan zakat sebagai berikut;

1. Pola Pengumpulan Zakat

Pemerintah tidak melakukan pengumpulan zakat. Melainkan hanya berfungsi sebagai Motivator, Regulator, dan fasilitator dalam pegumpulan zakat. Pengumpulan zakat dilakukan oleh 
badan amil zakat yang dibentuk oleh pemerintah dan lembaga amil zakat yang dibentuk oleh masyarakat dan dikukuhkan oleh pemerintah. Pengumpulan zakat dapat dilakukan melalui penyerahan langsung (datang) ke Badan Amil Zakat melalui conter zakat, unit pengumpulan zakat, pos, bank, pemotongan gaji, dan pembayaran zakat yang dapat mengurangi penghasilan kena pajak.

2. Pola Pendistribusian Zakat

Pola pendistribusian zakat adalah bentuk penyaluran dana zakat dari muzaki kepada mustahik dengan melalui amil. Penyaluran zakat dapat dibedakan menjadi dua bentuk, yakni bantuan sesaat (pola tradisonal/konsumtif) dan pemberdayaan (pola kontemporer/produktif). Pola tradisional yaitu penyaluran batuan dana zakat diberikan langsung kepada mustahik. Pola kontemporer/produktif (bantuan pemberdayaan) adalah pola penyaluran dana zakat kepada mustahik yang ada dipinjamkan oleh amil untuk kepentingan aktifitas suatu usaha/bisnis.

3. Pola Pendayagunaan Zakat

Pola pendayagunan zakat adalah cara/sistem distribusi dan alokasi dana zakat berdasarkan dengan tuntunan perkembangan zaman dan sesuai dengan cita dan rasa syari'at, pesan dan kesan ajaran islam. Sasaran Pendayagunaan Zakat Allah SWT menetapkan delapan golongan mustahik (asnaf Mustahik). Terdiri dari fakir, miskin, amil, muallaf, riqob, ghorimin, fisabilillah, dan ibnu sabil.

Penelitian Sartika (2008) dengan judul "Pengaruh pendayagunaan zakat produktif terhadap pemberdayaan mustahiq pada LAZ Yayasan Solo Peduli" membuktikan bahwa jumlah dana yang disalurkan LAZ berpengaruh signifikan antara terhadap pendapatan mustahiq. Ini berarti bahwa jumlah dana (zakat) yang disalurkan benar-benar mempengaruhi pendapatan mustahiq, dengan kata lain semakin tinggi dana yang disalurkan maka akan semakin tinggi pula pendapatan mustahiq.

Hasil penelitian Multifiah (2009) dengan judul,"pengaruh zakat, infak, sedekah (ZIS) terhadap kesejahteraan rumah tangga 
miskin" menunjukkan bahwa secara simultan variabel-variabel bantuan modal, bantuan beasiswa, bantuan biaya kesehatan, dan lama menerima bantuan, berpengaruh signifikan terhadap variabel dependen rumah tangga miskin.

\section{Metode Penelitian}

Jenis penelitian adalah deskriptif kualitatif. Pendekatan deskriptif kualitatif digunakan untuk menjelaskan kondisi faktual dan menemukan solusi dari permasalahan yanga ada di organisasi pengelola zakat, infak dan sedekah (OPZ) yang menjadi fokus penelitian. Penelitian ini juga termasuk penelitian survei digunakan untuk mengetahui persepsi para muzaki, amil, mustahiq dan masyarakat.

\section{Analisis}

Pada bagian ini diuraikan hasil penelitian tentang potensi zakat, infak, dan sedekah di Kabupaten Jember, sistem dan metode penggalangan, pendistribusian, pengelolaan zakat, infak dan sedekah, laporan keuangan organisasi pengelola zakat, akuntabilitas organisasi pengelola zakat, persepsi muzaki terhadap pembayaran dan pengelolaan ZIS pada OPZ dan persepsi mustahiq terhadap kebermanfaatan zakat, infak dan sedekah.

Potensi sumber dana zakat, infak, dan sedekah di Kabupaten Jember

Bagian ini diuraikan hasil penelitian tentang potensi zakat, infak, dan sedekah di Kabupaten Jember.

\section{Tabel 1}

Jumlah (Rp.000) dan Perkembangan(\%) Dana ZIS di Kab. Jember

\begin{tabular}{|c|c|c|c|c|c|c|c|c|c|c|}
\hline \multirow{2}{*}{ No } & \multirow{2}{*}{ Nama OPZ } & \multirow{2}{*}{$\begin{array}{l}2007 \\
\text { Rp. }\end{array}$} & \multicolumn{2}{|c|}{2008} & \multicolumn{2}{|c|}{2009} & \multicolumn{2}{|c|}{2010} & \multicolumn{2}{|c|}{2011} \\
\hline & & & Rp. & $\%$ & Rp. & $\%$ & Rp. & $\%$ & Rp. & $\%$ \\
\hline 1 & $\begin{array}{l}\text { Yayasan Dana Sosial Al } \\
\text { Falah (YDSF) }\end{array}$ & 40.000 & 45.000 & 12 & 50.000 & 10 & 55.000 & 10 & 60.000 & 9 \\
\hline 2 & $\begin{array}{l}\text { Lembaga Amil Zakat } \\
\text { Kementrian Agama }\end{array}$ & 31.016 & 31.252 & 8 & 40.880 & 31 & 71.978 & 76 & 110.991 & 54 \\
\hline 3 & $\begin{array}{l}\text { Rumah Itqon Zakat } \\
\text { Infak (Rizki) }\end{array}$ & 348.810 & 523.308 & 20 & 669.461 & 28 & 849.718 & 27 & 977.063 & 15 \\
\hline 4 & Azka Al Baitul Amil & 0 & 54.553 & - & 80.457 & 47 & 125.391 & 56 & 142.278 & 13 \\
\hline
\end{tabular}




\begin{tabular}{llccccccccc}
\hline 5 & Baitul Maal & \multirow{2}{*}{15.000} & 16.000 & 7 & 16.500 & 3 & 17.500 & 6 & 19.000 & 9 \\
& Hidayatullah (BMH) & & & & & & & & & \\
6 & Yatim Mandiri & 0 & 112.810 & - & 430.372 & 282 & 844.476 & 96 & 1.215 .182 & 44 \\
7 & LAZISMU & 47.059 & 106.945 & 127 & 107.536 & 1 & 114.172 & 6 & 122.561 & 7 \\
& $\quad$ Total & $\mathbf{5 6 7 . 8 8 5}$ & $\mathbf{8 8 9 . 8 7 0}$ & $\mathbf{5 7}$ & $\mathbf{1 . 3 9 5 . 2 0 8}$ & $\mathbf{5 7}$ & $\mathbf{2 . 0 7 8 . 2 3 7}$ & $\mathbf{4 9}$ & $\mathbf{2 . 6 4 7 . 0 7 6}$ & $\mathbf{2 7}$ \\
\hline
\end{tabular}

Sumber: kuesioner (data diolah)

Secara keseluruhan jumlah dana ZIS yang telah dikumpulkan oleh tujuh (7) organisasi pengelola zakat YDSF, Kemenag, Rizki, Azka Al Baitul Amil, BMH, Yatim Mandiri dan LAZISMU pada tahun 2007 sebesar Rp. 567.885.000 dan pada tahun 2008 sebesar Rp. 889.870.000 atau naik sebesar 57\%. Pada tahun 2009 mampu mengumpulkan dana ZIS sebesar Rp. 1.395.208.000 atau naik 57\% dibandingkan tahun 2008. Tahun 2010 jumlah dana ZIS yang dikumpulkan dan dikelola oleh tujuh (7) OPZ sebesar Rp. 2.078.237.000 atau tumbuh 49\%. Pada tahun 2011, tujuh (7) OPZ di Jember telah mengumpulkan dana ZIS sebesar Rp. 2.647.076.000 atau berkembang sebesar 27\%. Berdasarkan jumlah dana zakat, infak dan shodaqoh (ZIS) yang telah dikumpulkan oleh tujuh (7) organisasi pengelola ZIS pada tahun 2007 sampai dengan tahun 2011 sebesar Rp. 7.578.278.000 dengan rata-rata pertumbuhan tiap tahun sebesar $47,5 \%$ maka dapat disimpulkan bahwa potensi dana ZIS dari muzaki yang dapat dikumpulkan oleh organisasi pengelola zakat di Kabupaten Jember sangat tinggi;

Tabel 2

Jumlah dan Pertumbuhan Muzaki di Kab. Jember

\begin{tabular}{llcccccccccc}
\hline \multirow{2}{*}{ No } & \multirow{2}{*}{ Nama OPZ } & \multicolumn{2}{c}{2007} & \multicolumn{2}{c}{2008} & \multicolumn{2}{c}{2009} & \multicolumn{2}{c}{2010} & \multicolumn{2}{c}{2011} \\
\cline { 2 - 9 } & Orang & orang & $\%$ & orang & \% & orang & \% & orang & \% \\
\hline 1 & YDSF & 2.000 & 2.250 & 13 & 2.500 & 11 & 2.750 & 10 & 3.000 & 9 \\
2 & Kemenag & 1.600 & 1.625 & 2 & 1.912 & 18 & 3.115 & 63 & 5.367 & 72 \\
3 & Rizki & 907 & 973 & 7 & 1.000 & 3 & 1.012 & 1 & 1.320 & 30 \\
4 & Azka Al Baitul Amil & 0 & 847 & - & 1.735 & 105 & 2.544 & 47 & 3.577 & 41 \\
5 & BMH & 475 & 500 & 5 & 525 & 5 & 550 & 5 & 640 & 16 \\
6 & Yatim Mandiri & 0 & 500 & - & 1000 & 100 & 1800 & 80 & 2800 & 56 \\
7 & LAZISMU & 150 & 250 & 67 & 300 & 20 & 400 & 33 & 500 & 25 \\
& \multirow{2}{*}{ Total } & $\mathbf{5 . 1 3 2}$ & $\mathbf{6 . 9 4 5}$ & $\mathbf{3 5}$ & $\mathbf{8 . 9 7 2}$ & $\mathbf{2 9}$ & $\mathbf{1 2 . 1 7 1}$ & $\mathbf{3 6}$ & $\mathbf{1 7 . 2 0 4}$ & $\mathbf{4 1}$ \\
\hline
\end{tabular}

Sumber: kuesioner (data diolah) 
Secara keseluruhan jumlah muzaki yang telah membayar ZIS pada tujuh (7) organisasi pengelola zakat YDSF, Kemenag, Rizki, Azka Al Baitul Amil, BMH, Yatim Mandiri dan LAZISMU pada tahun 2007 sejumlah 5.132 orang dan pada tahun 2008 sebesar 6.945 orang atau naik sebesar 35\%. Pada tahun 2009 jumlah muzaki sebesar 8.972 orang atau naik 29\% dibandingkan tahun 2008. Tahun 2010 jumlah muzaki pada tujuh (7) organisasi pengelola zakat sebesar 12.171 orang atau tumbuh 36\%. Pada tahun 2011, muzaki yang telah membayar dana ZIS sebanyak 17.204 orang atau berkembang sebesar $41 \%$. Berdasarkan jumlah muzaki yang telah membayar ZIS pada tujuh (7) organisasi pengelola zakat pada tahun 2007 sampai dengan tahun 2011 sejumlah 17.204 orang dengan ratarata pertumbuhan tiap tahun sebesar sebesar 28,2\% maka dapat disimpulkan bahwa potensi pembayar ZIS (muzaki) di Kabupaten Jember sangat tinggi;

Tabel 3

Jumlah dan Pertumbuhan Penyaluran Dana ZIS di Kab. Jember

\begin{tabular}{|c|c|c|c|c|c|c|c|c|c|c|}
\hline \multirow{2}{*}{ No } & \multirow{2}{*}{ Nama OPZ } & \multirow{2}{*}{$\begin{array}{c}2007 \\
\text { Rp }\end{array}$} & \multicolumn{2}{|c|}{2008} & \multicolumn{2}{|l|}{2009} & \multicolumn{2}{|l|}{2010} & \multicolumn{2}{|l|}{2011} \\
\hline & & & $\mathbf{R p}$ & $\%$ & $\mathbf{R p}$ & $\%$ & $\mathbf{R p}$ & $\%$ & Rp & $\%$ \\
\hline 1 & YDSF & 32.000 & 37.000 & 16 & 42.000 & 14 & 47.000 & 12 & 52.000 & 11 \\
\hline 2 & Kemenag & 18.700 & 20.050 & 7 & 23.000 & 16 & 31.940 & 39 & 43.875 & 37 \\
\hline 3 & Rizki & 441.109 & 511.484 & 16 & 658.732 & 29 & 848.708 & 29 & 970.942 & 14 \\
\hline 4 & Azka Al Baitul Amil & 0 & 43.875 & - & 71.335 & 63 & 83.984 & 18 & 57.973 & -31 \\
\hline 5 & $\mathrm{BMH}$ & 9.000 & 9.000 & 0 & 9.500 & 6 & 8.000 & -16 & 8.000 & 0 \\
\hline 6 & Yatim Mandiri & 0 & 78.967 & - & 301.260 & 282 & 591.133 & 96 & 850.627 & 44 \\
\hline 7 & LAZISMU & 27.260 & 104.613 & 284 & 115.211 & 10 & 109.809 & -5 & 107.207 & -2 \\
\hline & Total & 528.069 & 804.990 & 52 & 1.221 .040 & 52 & 1.720 .575 & 41 & 2.090 .625 & 22 \\
\hline
\end{tabular}

Sumber: kuesioner (data diolah)

Secara keseluruhan tujuh (7) organisasi pengelola zakat YDSF, Kemenag, Rizki, Azka Al Baitul Amil, BMH, Yatim Mandiri dan LAZISMU pada tahun 2007 jumlah dana ZIS telah menyalurkan dana zakat, infak dan sedekah (ZIS) kepada para mustahiq sebesar Rp. 528.069.000 dan pada tahun 2008 sebesar Rp. 804.990.000 atau naik sebesar 52\%. Pada tahun 2009 mampu menyalurkan dana ZIS sebesar Rp. 1.221.040.000 atau naik 52\% dibandingkan tahun 2008. Tahun 2010 jumlah dana ZIS yang disalurkan oleh tujuh (7) organisasi pengelola zakat kepada mustahiq sebesar 
Rp. 1.720.575.000 atau tumbuh 41\%. Pada tahun 2011, tujuh (7) organisasi pengelola zakat telah menyalurkan dana ZIS sebesar Rp. 2.090.625.000 atau berkembang sebesar 22\%. Berdasarkan jumlah dana ZIS yang telah disalurkan oleh tujuh (7) organisasi pengelola zakat para mustahiq pada tahun 2007 sampai dengan tahun 2011 sebesar Rp. 6.365.301.000 dengan rata-rata pertumbuhan tiap tahun sebesar $41,75 \%$ maka dapat disimpulkan bahwa potensi dana ZIS yang disalurkan kepada mustahiq di Kabupaten Jember sangat tinggi;

\section{Tabel 4}

Jumlah dan Pertumbuhan Mustahiq/Penerima ZIS di Kab. Jember

\begin{tabular}{|c|c|c|c|c|c|c|c|c|c|c|}
\hline \multirow{2}{*}{ No } & \multirow{2}{*}{ Nama OPZ } & \multirow{2}{*}{$\begin{array}{c}2007 \\
\text { orang } \\
\end{array}$} & \multicolumn{2}{|c|}{2008} & \multicolumn{2}{|c|}{2009} & \multicolumn{2}{|c|}{2010} & \multicolumn{2}{|c|}{2011} \\
\hline & & & orang & $\%$ & orang & $\%$ & orang & $\%$ & orang & $\%$ \\
\hline 1 & YDSF & 224 & 248 & 11 & 269 & 8 & 285 & 6 & 304 & 7 \\
\hline 2 & Kemenag & 137 & 144 & 5 & 149 & 3 & 156 & 5 & 161 & 3 \\
\hline 3 & Rizki & 7.474 & 6.391 & -14 & 8.413 & 32 & 5.228 & -38 & 7.947 & 52 \\
\hline 4 & Azka Al Baitul Amil & 0 & 441 & - & 480 & 9 & 593 & 24 & 662 & 12 \\
\hline 5 & $\mathrm{BMH}$ & 139 & 130 & -5 & 140 & 8 & 110 & -21 & 110 & 0 \\
\hline 6 & Yatim Mandiri & 0 & 191 & - & 395 & 107 & 483 & 22 & 1.084 & 124 \\
\hline 7 & LAZISMU & 198 & 1.815 & 817 & 1.927 & 6 & 1.832 & -5 & 1.821 & -1 \\
\hline & Total & 8.172 & 9.360 & 15 & 11.773 & 26 & 8.687 & -26 & 12.089 & 39 \\
\hline
\end{tabular}

Sumber: kuesioner (data diolah)

Secara keseluruhan jumlah mustahiq/penerima dana zakat, infak dan sedekah (ZIS) yang telah menerima dari tujuh (7) organisasi pengelola zakat pada tujuh (7) organisasi pengelola zakat YDSF, Kemenag, Rizki, Azka Al Baitul Amil, BMH, Yatim Mandiri dan LAZISMU pada tahun 2007 sejumlah 8.172 orang dan pada tahun 2008 sebesar 9.360 orang atau naik sebesar 13\%. Pada tahun 2009 jumlah muzaki sebesar 11.773 orang atau naik 20\% dibandingkan tahun 2008. Tahun 2010 jumlah muzaki pada tujuh (7) organisasi pengelola zakat sebesar 8.687 orang atau tumbuh -36\%. Pada tahun 2011, mustahiq yang telah menerima dana ZIS dari tujuh (7) organisasi pengelola zakat YDSF, Kemenag, Rizki, Azka Al Baitul Amil, BMH, Yatim Mandiri dan LAZISMU sebanyak 12.089 orang atau berkembang sebesar 28\%. Berdasarkan jumlah mustahiq/penerima dana zakat, infak dan sedekah (ZIS) yang telah menerima dari tujuh (7) organisasi pengelola zakat pada tujuh 
(7) organisasi pengelola zakat pada tahun 2007 sampai dengan tahun 2011 sejumlah 12.089 orang dengan rata-rata pertumbuhan tiap tahun sebesar 6,4\% maka dapat disimpulkan bahwa potensi mustahiq yang menerima dana ZIS dari organisasi pengelola zakat di Kabupaten Jember sangat tinggi.

Sistem dan metode penggalangan, pengelolaan, dan pendistribusian yang dilakukan oleb lembaga-lembaga pengelola zakat, infak, dan sedekah.

Sistem atau metode yang digunakan untuk menghimpun/ menggalang dana zakat, infak dan sedekah dari muzaki/donator yang dilakukan oleh tujuh (7) organisasi pengelola zakat antara lain YDSF, Kemenag, Rizki, Azka Al Baitul Amil, BMH, Yatim Mandiri dan LAZISMU adalah: a) pengelola ZIS aktif menarik ke muzaki; b) melalui unit pengumpulan zakat; c) melalui bank; d) presentasi ke instansi-instansi; e) memanfaatkan dana CSR; f) penyerahan dananya dilakukan secara langsung ke lembaga; g) melalui pemotongan gaji instansi masing-masing muzaki; h) juga dilakukan dengan SMS pada masing-masing muzaki;

Pengelolaan dana zakat, infak dan sedekah dari muzaki/ donator yang dilakukan oleh tujuh (7) organisasi pengelola zakat adalah; a) dikelola oleh tenaga/sumber daya insani OPZ cukup professional; b) penghimpunan dana ZIS sudah dilaksanakan dengan baik; c) penyaluran dana ZIS sudah dilaksanakan dengan baik; d) sistem pengendalian internal dilaksanakan dengan baik; e) laporan keuangan belum dibuat secara lengkap oleh ke tujuh (7) OPZ di kabupaten Jember kecuali Yatim Mandiri telah menyusun empat (4) bentuk laporan keuangan; f) laporan keuangan yang dibuat Depag, Rizki, Azka, BMH dan LAZISMU hanya diaudit oleh pihak internal sedangkan yang dibuat Yatim Mandiri YDSF sudah diaudit oleh pihak internal maupun pihak eksternal; g) mekanisme pertanggungjawaban dilaksanakan dengan baik dan disampaikan kepada muzaki/donatur dan lembaga/bagian syariah; h) OPZ yang mempunyai Standard Operation Procedure (SOP) adalah YDSF, Rizki, BMH, Yatim Mandiri dan LAZISMU sedangkan Depag dan Azka belum memiliki; i) OPZ yang mempunyai internal auditor adalah YDSF, Depag, Rizki, BMH, Yatim Mandiri dan LAZISMU 
sedangkan Azka tidak mempunyai internal auditor; j) OPZ yang memiliki dewan/lembaga pengawas syari'ah adalah Depag, Rizki, BMH, Yatim Mandiri, LAZISMU dan YDSF sedangkan Azka tidak memiliki dewan/lembaga pengawas syari'ah; k) keterlibatan dewan/ lembaga pengawas syariah dalam pengambilan keputusan selalu dilibatkan pada Depag dan LAZISMU. Sedangkan pada Rizki, BMH Yatim Mandiri hanya jika ada masalah serius dalam mengambil keputusan. Namun pada YDSF jarang sekali dilibatkan dalam mengambil keputusan; 1) frekuensi pelaporan pengelolaan dana ZIS oleh YDSF, Depag, BMH, Yatim Mandiri, LAZISMU setiap 1 bulan, sedangkan Rizki dan Azka melaporkan kepada muzaki adalah 3 atau 4 bulan; m) media yang digunakan untuk memberitahukan penglolaan dana adalah majalah, papan pengumuman, surat/ laporan langsung kepada muzakki buletin, dan internet;

Akuntabilitas lembaga pengelola zakat, infak, dan sedekab telah cukup memadai.

Laporan keuangan yang disampaikan kepada muzakki dan publik oleh OPZ adalah sebagai berikut: a) YDSF hanya melaporkan laporan sumber dan penyaluran dana ZIS; b) Depag hanya melaporkan laporan sumber dan penyaluran dana ZIS; c) Rizki melaporkan neraca dan laporan arus kas; d) Azka hanya melaporkan laporan sumber dan penyaluran dana ZIS; e) $\mathrm{BMH}$ hanya melaporkan catatan atas laporan keuangan; f) Yatim Mandiri melaporkan laporan sumber dan penyaluran dana ZIS; g) LAZISMU melaporkan neraca, laporan sumber dan penyaluran dana ZIS.

Organisasi pengelola zakat di Kabupaten Jember menerapkan prinsip akuntabilitas yang meliputi hal-hal berikut; a) Pengelolaan ZIS sudah sesuai dengan hukum/ peraturan yang berlaku; b) pelaksanaan penggalangan dana sesuai dengan aturan dan prosedur; c) pelaksanaan pendistribusian dana sesuai dengan aturan dan prosedur; d) program yang dijalankan sesuai dengan komitmen organisasi; e) program-progam tersebut telah berjalan dengan baik; f) kebijakan yang diambil sesuai dengan pertanggungjawaban pengelola; g) lembaga zakat dalam mengelola dana sesuai dengan syariah Islam; h) lembaga zakat dalam mengelola dana belum sesuai dengan prosedur operasional lembaga zakat yang berlaku; i) 
pelaksanaan/kegiatan program lembaga zakat dalam mengelola dana sudah sesuai dengan program yang telah ditentukan sebelumnya; j) pelaksanaan program lembaga zakat dalam mengelola dana berjalan dengan baik; k) pelaksanaan/kegiatan program lembaga zakat dalam mengelola dana sudah sesuai dengan komitmen lembaga zakat; 1) pelaksanaan/kegiatan program lembaga zakat dalam mengelola dana sudah sesuai dengan kebijakan lembaga zakat, lembaga zakat dalam menggalang dana dari muzaki sudah sesuai dengan ketentuan hukum syariah Islam; m) lembaga zakat dalam menggalang dana dari muzaki belum sesuai dengan prosedur operasional lembaga zakat yang berlaku; n) lembaga zakat dalam menggalang dana dari muzaki sudah tepat sasaran; o) lembaga zakat dalam mendistribusikan dana kepada mustahiq sudah sesuai dengan ketentuan hukum syariah Islam; p) lembaga zakat dalam mendistribusikan dana kepada mustahiq sudah sesuai dengan prosedur operasional lembaga zakat yang berlaku; q) lembaga zakat dalam mendistribusikan dana pada mustahiq tepat sasaran;

Kebermanfaatan dana tersebut bagi penerima zakat, infak, dan sedekah.

Persepsi muzaki terhadap pembayaran dan pengelolaan zakat, infak dan sedekah pada pada tujuh (7) organisasi pengelola zakat (OPZ); Yayasan Dana Sosial Al Falah (YDSF), Lembaga Amil Zakat Kementrian Agama, Rumah Itqon Zakat Infak (Rizki), Azka Al Baitul Amil, Baitul Maal Hidayatullah (BMH), Yatim Mandiri dan Lembaga Amil Zakat Infak dan Sedekah Muhammadiyah (LAZISMU) sebagai berikut; a) mampu memecahkan permasalahan ekonomi masyarakat miskin; b) membayar zakat di LAZ termasuk juga dalam berinvestasi baik dunia maupun akhirat; c) membayar zakat merupakan ibadah yang wajib dilaksakan, dimana membayar zakat setara dengan mengerjakan shalat; d) membayar zakat merupakan salah satu sarana untuk memperlancar proses ekonomi dengan 
memberi penyaluran dana pada masyarakat miskin; e) persyaratan yang diperlukan dalam penyaluran zakat di LAZ mudah; f) LAZ dianggap sangat transparan dalam penyaluran zakatnya; g) zakat yang disalurkan melalui LAZ sangat cepat disalurkan oleh amil; h) adanya keramahan yang bersahaja pada karyawan di LAZ sehingga menarik minat muzaki dalam penyaluran zakatnya; i) pengelolaan yang dilakukan oleh LAZ sudah sangat baik; j) cara menyalurkan zakat kepada LAZ baik diberikan secara langsung maupun transfer melalui bank serta delivery; k) mudahnya persyaratan untuk menjadi muzaki, yang menjadi pertimbangan untuk menggunakan LAZ; 1) dekatnya jarak lembaga tersebut dengan tempat tinggal menjadi pertimbangan muzaki; m) LAZ merupakan lembaga yang memperoleh kepercayaan yang baik dari masyarakat; n) banyak kebaikan yang diperoleh muzaki dengan membayar zakat di LAZ; o) laporan keuangan yang dipublikasikan setiap periode tertentu sehingga lembaga ini sangat bersifat transparan.

\section{Model Revitalisasi Lembaga Pengelola Zakat}

Berdasarkan permasalahan yang dihadapi oleh OPZ serta hasil penelitian maka kami berkesimpulan bahwa OPZ perlu melakukan revitalisasi. Model revitalisasi yang diusulkan adalah model tiga lingkaran (Three Circles Model). Model yang dibuat mengacu pada Lingkaran yang mempengaruhi dan dipengaruhi oleh adanya pembayaran zakat, infak dan sedekah (ZIS).

Secara garis besar kami membagi Lingkaran ZIS menjadi tiga bagian, yaitu Lingkaran muzaki-amil (untuk selanjutnya disebut siklus muzaki), Lingkaran mustahiq-amil (untuk selanjutnya disebut siklus mustahiq) dan Lingkaran muzaki-amil-mustahiq. Untuk lebih jelasnya model Three cyrcles lembaga pengelola zakat bisa dilihat pada gambar di bawah ini. 


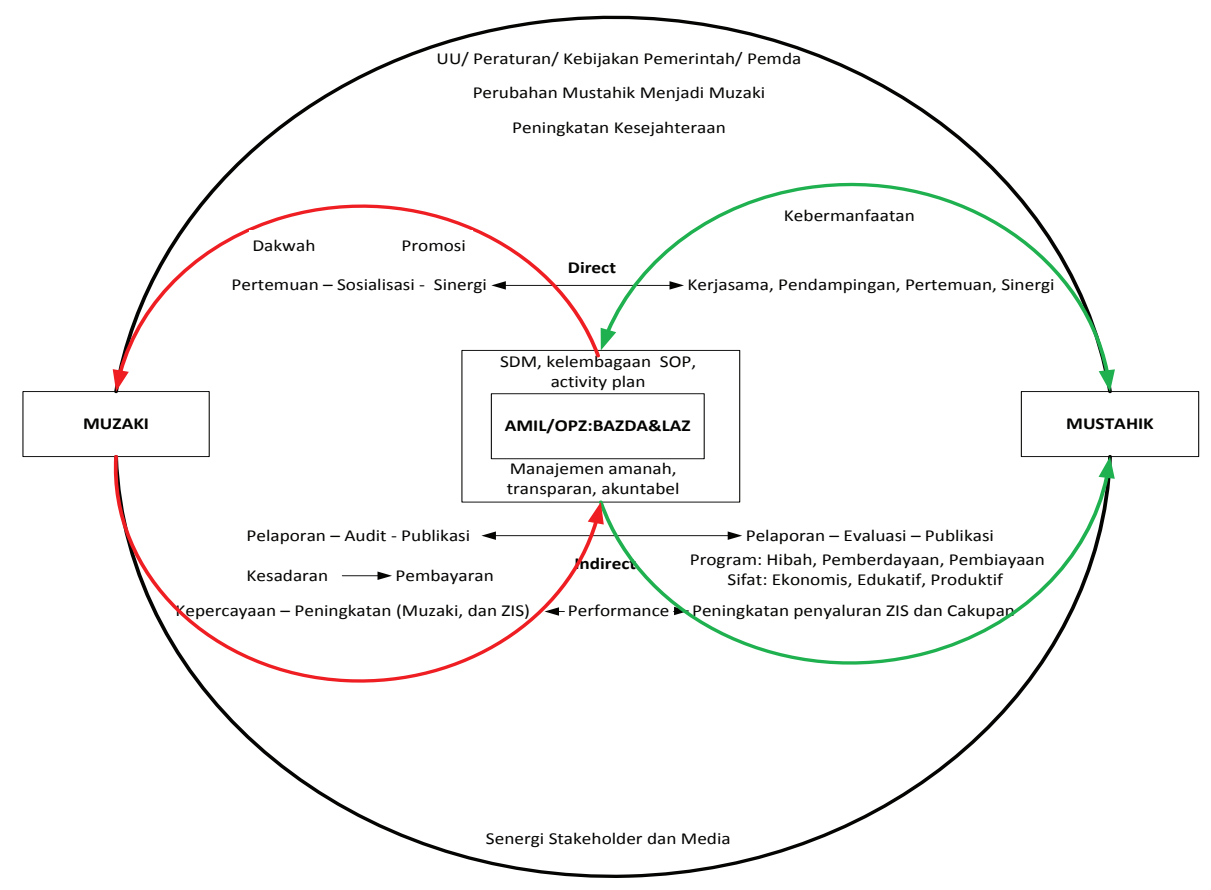

Sumber: Data terolah

\section{Gambar 1}

Three Circles Model Revitalisasi Lembaga Pengelola Zakat

Penjelasan mengenai mengenai tiga Lingkaran tersebut akan dibahas sebagai berikut:

\section{Lingkaran Pertama (Lingkaran Merah)}

Lingkaran pertama menunjukkan interaksi antara amil dan muzaki baik dengan cara direct maupun indirect methods. Dalam rangka meningkatkan jumlah muzaki, OPZ perlu melakukan kegiatan promosi dan dakwah untuk meningkatkan kesadaran masyarakat dalam membayar ZIS. OPZ perlu menyakinkan kepada para muzaki bahwa dana ZIS dikelola secara amanah sesuai dengan syariah Islam dan dipertanggungjawabkan secara transaparan kepada setiap muzaki baik secara langsung atau melalui media, majalah, website (internet). Disamping itu OPZ perlu mengadakan 
pertemuan secara langsung dengan para muzaki secara rutin minimal setahun sekali dalam rangka mempererat hubungan, menyampaikan program yang sudah dan akan dilaksanakan, manfaat ZIS yang telah diperoleh para mustahiq. Lingkaran pertama yang digambarkan secara dinamis berputar dan semakin membesar menunjukkan bahwa dengan keberhasilan manajemen OPZ mampu memelihara dan meningkatkan jumlah muzaki semakin bertambah.

Dalam rangka mengoptimalkan hasil penghimpunan ZIS maka OPZ perlu membentuk Unit Pengumpul Zakat yang bertujuan memberi kemudahan para muzaki untuk membayar zakatnya. Selain membuka Unit Pengumpul Zakat di berbagai tempat, OPZ dapat membuka loket tempat pembayaran zakat di kantor atau sekretariat lembaga yang bersangkutan. OPZ perlu membuka rekening pembayaran zakat, infak, dan sedekah di bank dan dipublikasikan secara luas kepada masyarakat agar memudahkan para muzaki untuk membayar ZIS. Diperlukan penguatan kelembagaan karena OPZ yang mampu penggalangan dana ZIS, ternyata didukung oleh kelembagaan yang kuat juga. Kelengkapan regulasi sangat mendukung upaya meningkatkan jumlah ZIS. Perlu jumlah tenaga fundraising yang memadai dan didukung oleh kemampuan dan fasilitas yang memadai. Disamping itu perlu sosialisasi yang memadukan penyampaian informasi tentang fikih zakat, regulasi dan keunggulan program pendayagunaan ZIS. Sosilisasi dilakukan dalam bentuk forum pertemuan, diskusi, seminar, publikasi media, baliho, spanduk, film/video, leaflet/brosur/booklet, portal website, billboard/banner, khutbah jum'at, dan gerakan sadar zakat. Disamping itu OPZ perlu juga memperkuat pubikasi dan teknologi informasi, sehingga akan terbangun kepercayaan masyarakat dan semakin mudahnya masyarakat menyampaikan ZIS-nya untuk dikelola oleh OPZ. Amil OPZ harus mampu menerapkan manajemen penghimpunan dana ZIS yang baik, amanah, transparan dan akuntabel. Oleh karena itu amil harus memiliki SDM yang professional. SDM bagian pengumpulan dana harus amanah, jujur mempunyai keahlian dan pengalaman di bidang marketing dan kemampuan komunikasi yang baik dan mampu bekerjasama dalam tim. SDM bagian keuangan harus amanah, jujur, cermat dan teliti mempunyai keahlian dan pengalaman di bidang akuntansi dan 
manajemen keuangan dan mampu bekerjasama dalam tim.

OPZ harus didukung oleh sistem, prosedur dan aturan yang jelas. Semua kebijakan dan ketentuan dibuat aturan mainnya secara jelas dan tertulis sehingga keberlangsungan lembaga tidak bergantung kepada figur seseorang, tetapi kepada sistem. Jika terjadi pergantian SDM sekalipun, aktivitas lembaga tidak akan terganggu karenanya.

OPZ harus dikelola dengan menerapkan manajemen terbuka. Ada hubungan timbal balik antara amil selaku pengelola dengan masyarakat sehingga terjadi sistem kontrol yang melibatkan unsur luar, yaitu masyarakat itu sendiri. OPZ dikelola berdasarkan rencana kerja (activity plan). Rencana kerja disusun berdasarkan kondisi lapangan dan kemampuan sumber daya lembaga sehingga aktivitas OPZ akan terarah dan target akan mudah tercapai. OPZ juga harus memiliki sistem akuntansi dan manajemen keuangan yang baik untuk menunjang akuntabilitas dan transparansi, menjamin keamanan dana relatif lebih terjamin, semua transaksi relatif akan lebih mudah ditelusuri dan menjamin efisiensi dan efektivitas operasional OPZ.

Laporan keuangan dan hasil operasional OPZ harus diaudit baik oleh auditor internal maupun eksternal. Auditor internal diwakili oleh Komisi Pengawas atau internal auditor. Sedangkan auditor eksternal dapat diwakili oleh Kantor Akuntan Publik atau lembaga audit independen lainnya. Semua yang telah dilakukan oleh OPZ harus disampaikan kepada publik, sebagai bagian dari pertanggungjawaban dan transparan-nya pengelola. Caranya dapat melalui media massa seperti surat kabar, majalah, buletin, radio, TV, dikirim langsung kepada para donatur, atau ditempel di papan pengumuman yang ada di kantor OPZ yang bersangkutan. Hal-hal yang perlu dipublikasikan antara lain laporan keuangan, laporan kegiatan dan nama-nama penerima bantuan.

Akhirnya setiap kegiatan penghimpunan dana harus dievaluasi, dan dimonitoring untuk dilakukan perbaikan dan peningkatan dilakukan secara terus-menerus tanpa henti. Jika semua hal yang telah diusulkan dalam model lingkaran satu akan meningkatkan kepercayaan muzaki/pembayar ZIS sehingga 
akan menambah jumlah muzaki/pembayar ZIS sekaligus akan meningkatkan jumlah ZIS yang dibayar. Dengan demikian lingkaran satu akan selalu berputar secara dinamis membentuk lingkaran yang semakin besar sebagai gambaran semakin banyak jumlah orang yang membayar(muzaki) ZIS dan semakin besar jumlah ZIS. Hal ini akan meningkatkan kinerja penghimpuan dana ZIS.

\section{Lingkaran Kedua (Lingkaran Hijau)}

Lingkaran kedua menunjukkan interaksi antara amil dan mustahiq baik dengan cara direct maupun indirect methods. Dalam rangka mengelola penyaluran dana ZIS, OPZ perlu aktif melakukan penyaluran ZIS sesuai syariah dan tepat sasaran. Dimulai dari kriteria penentuan siapa saja yang akan diberi penyaluran dananya, berapa besarnya dana yang akan disalurkan dan bagaimana proses yang akan dipilih dalam penyaluran dana ZIS. Dana ZIS seharusnya bisa diberikan dengan tiga cara yaitu yaitu bantuan tunai langsung, pemberdayaan masyarakat dan bantuan dana bergulir. Dana ZIS hendaknya disalurkan untuk kegiatan produktif agar mustahiq yang dibantu segera berdaya ekonominya sehingga mampu meningkatkan pendapatan keluarga. Dengan memberdayakan dana ZIS dalam bentuk kegiatan produktif diharapkan dalam jangka menengah bisa merubah mustahiq yang awalnya menerima dana ZIS akan menjadi muzaki yaitu orang yang akan membayar ZIS. OPZ perlu melakukan pertemuan secara langsung dengan seluruh mustahiq agar dapat diketahui kendala dan manfaat dari penyaluran dana ZIS sehinga ada umpan balik dan akan diketahui solusi pemecahan permasalahan yang terkait dengan penyaluran dana ZIS. Lingkaran kedua yang digambarkan secara dinamis berputar dan semakin membesar menunjukkan bahwa dengan keberhasilan manajemen OPZ dalam menyalurkan dana ZIS mampu meningkatkan status mustahiq menjadi muzaki namun juga OPZ mampu meningkatkan cakupan mustahiq yang bisa dibantu oleh OPZ.

Penyaluran dana ZIS kepada mustahiq harus berdasarkan prinsip amanah, transaparan dan dapat dipertanggungjawabkan. Bentuk penyaluran dana dapat berupa bantuan tunai langsung (hibah). Zakat pada asalnya harus diberikan berupa hibah artinya tidak ada ikatan antara pengelola dengan mustahiq setelah 
penyerahan zakat. Bentuk penyaluran bantuan tunai langsung hanya diberikan kepada para mustahiq yang tergolong tua renta yang tidak mampu menjalankan pekerjaan. Apabila mustahiq miskin karena menganggur namun masih mempunyai kekuatan fisik untuk bekerja dan berusaha maka bentuk penyaluran dana ZIS berupa pemberdayaan. Mustahiq yang tidak punya keahlian untuk bekerja dan berusaha sebaiknya di beri ketrampilan dan keahlian sehingga setelah memperoleh ketrampilan dan keahlian maka diharapkan mustahiq mampu bekerja atau menjalankan usaha. Bentuk penyaluran yang ketiga adalah dana bergulir. Dana ZIS dapat diberikan berupa dana bergulir oleh pengelola kepada mustahiq dengan catatan harus qardhul hasan, artinya tidak boleh ada kelebihan yang harus diberikan oleh mustahiq kepada pengelola ketika pengembalian pinjaman tersebut. Jumlah pengembalian sama dengan jumlah yang dipinjamkan.

Amil harus mampu menerapkan manajemen penyaluran dana ZIS yang baik, amanah, ranspartan dan akuntabel. Oleh karena itu amil harus memiliki SDM yang professional. SDM bagian pendayagunaan harus amanah, jujur mempunyai keahlian dan pengalaman di bidang pembangunan masyarakat dan mampu bekerjasama. Kegiatan penyaluran dana ZIS harus didukung oleh sistem, prosedur dan aturan yang jelas. Setiap kegiatan penyaluran dana harus dikelola dengan menerapkan manajemen terbuka, berdasarkan rencana kerja (activity plan), memiliki sistem akuntansi dan manajemen keuangan penyaluran dana.

Semua kegiatan penyaluran dana ZIS yang telah dilakukan oleh OPZ harus disampaikan kepada publik, sebagai bagian dari pertanggungjawaban dan transparan-nya pengelola. Caranya dapat melalui media massa seperti surat kabar, majalah, buletin, radio, TV, dikirim langsung kepada para donatur, atau ditempel di papan pengumuman yang ada di kantor OPZ yang bersangkutan. Hal-hal yang perlu dipublikasikan antara lain laporan keuangan, laporan kegiatan dan nama-nama penerima bantuan.

Akhirnya setiap kegiatan penyaluran dana harus dievaluasi, dimonitoring untuk dilakukan perbaikan dan peningkatan dilakukan secara terus-menerus tanpa henti. Melakukan pembinaan dan 
pendampingan kepada para mustahiq dalam kegitan usahanya, juga harus memberikan pembinaan rohani dan intelektual keagamannya agar semakin meningkat kualitas keimanan dan keislamannya.

Jika semua hal yang telah diusulkan dalam model lingkaran dua akan meningkatkan kesejahteraan mustahiq. Setiap pembagian/ penyaluran dana ZIS harus bersifat edukatif, produktif dan ekonomis. Dengan demikian lingkaran dua akan selalu berputar secara dinamis membentuk lingkaran yang semakin besar dalam hal cakupan mustahiq yang didanai dan ditingkatkan kesejahteraan semakin luas. Namun sisi lain lingkaran kedua ini akan berangsur kecil sebagai gambaran semakin banyak penerima zakat menjadi tidak memerlukan zakat lagi, bahkan menjadi wajib zakat.

\section{Lingkaran Ketiga (Lingkaran Hitam)}

Lingkaran ketiga menunjukkan interaksi antara muzaki, amil dan mustahiq baik dengan cara direct maupun indirect methods. Ruang lingkup dalam Lingkaran muzaki-amil-mustahiq adalah interaksi yang terjadi selama proses penerimaan ZIS dan penyaluran ZIS kepada mustahiq. Model ini menjelaskan dalam rangka mengentaskan kemisikian dan meningkatkan kesejahteraan maka diperlukan keasadaran dan peran muzaki dalam menyediakan dana ZIS. Amil OPZ memiliki peranan dalam mengelola dan menyalurkan dana ZIS. Model ini mengadopsi peran Baitul Maal di zaman Rosulullah dan Pemerintahan Islam Khulafaur Rasyidin dalam mengelola dana ZIS sebagai sumber pendaanan dalam rangka meningkatkan kesejahteraan umat Islam. Dana ZIS yang dikumpulkan Baitul Maal disalurkan langsung kepada mustahiq. Meskipun saat ini masih banyak para muzaki menyalurkan dana ZIS langsung kepada mustahiq. Maka dengan model lingkaran satu dan dua diharapkan semua para muzaki mengalihkan dana ZIS melalui amil OPZ baik BAZDA maupun LAZ.

Aktivitas muzaki terhadap mustahiq melalui amil meliputi bagaimana amil dapat membuat sebuah kegiatan atau perencanaan yang memungkinkan para muzaki dapat bertatap muka dan berinteraksi dengan baik dengan para mustahiq. Kegiatan ini bisa dilakukan secara berkala atau secara kontinu. Semakin sering dan semakin mudah akses yang diberikan atau akses yang bisa dilalui 
oleh muzaki maka dampak kebermanfaatan dari ZIS akan semakin baik dan meningkat.

Aktivitas mustahiq kepada muzaki melalui amil mengacu bagaimana menumbuhkan rasa kebermanfaatan yang dirasakan oleh mustahiq ketika menerima ZIS dari muzaki. Dalam jangka panjang nilai-nilai inilah yang diharapkan akan tumbuh dan berkembang sehingga mustahiq yang mampu akan berubah menjada muzaki. Proses ini dapat ditumbuhkan oleh perencanaan yang baik dari amil dalam mengelola dan dan lembaganya. Ketepatan dalam penyaluran kredit, pendidikan dan pelatihan kewirausahaan dapat menjadi sebagian kecil contoh yang dapat diaplikasikan.

Lingkaran ketiga menunjukkan perlunya sinergi dengan berbagai stakeholder seperti muzaki, amil, mustahiq, pembuat kebijakan dan media massa Jika OPZ ingin berhasil dengan baik, maka ia harus mampu membangun kepercayaan para muzakki. Banyak cara yang bisa digunakan untuk mecapainya, antara lain: memberikan progress report berkala, mengundang muzaki ke tempat mustahiq, selalu menjalin komunikasi melalui media cetak dan silaturahmi.

Amil adalah faktor kunci keberhasilan pengumpul zakat. Untuk itu, lembaga tersebut harus mampu merekrut para amil yang amanah dan profesional. Setelah itu, pengumpul zakat juga harus mampu mendesain sistem operasional yang memberikan kesempatan kepada para amil untuk berkembang dan berkarya. Sehingga menjadi amil betul-betul merupakan sebuah pilihan dan pengabdian kepada Allah SWT. Para amil dalam bekerja harus meletakkan prinsip-prinsip seperti: ikhlas, sabar, amanah, jujur dan inovatif. Disamping itu, sistem operasional lembaga juga mesti mengakomodasikan kebutuhan para amil. Sehingga para amil dapat memberikan karyanya secara maksimal di dalam membangun lembaga tersebut.

Meskipun para mustahiq sebagai pihak penerima dana ZIS, mereka juga punya peranan dalam menyukseskan programprogram yang telah dicanangkan oleh amil OPZ. Mustahiq harus dapat bekerjasama dan mengikuti program-program bantuan yang dilakukan oleh amil. Jangan sampai pemberian bantuan 
justru menyebabkan mustahiq tidak mandiri secara ekonomi dan menjadikan seorang pemalas yang tidak mau bekerja maupun berusaha karena sudah mendapat bantuan dana ZIS. Setiap pembagian/penyaluran dana ZIS harus bersifat edukatif, produktif dan ekonomis semakin banyak penerima zakat menjadi tidak memerlukan zakat lagi, bahkan menjadi wajib zakat.

Kebijakan dalam konteks pemerintahan juga mempunyai pengaruh yang besar terhadap perkembangan pengumpul zakat. Dengan adanya peraturan seperti UU, maka lembaga tersebut akan dapat bergerak secara legal. Sehingga pengumpul zakat mempunyai landasan yang cukup kuat dalam mengelola zakat. Media merupakan penyambung lidah. Dengan begitu banyaknya oplah media diharapkan jangkauan sosialisasi kepada masyarakat akan semakin luas. Oleh karenanya pengumpul zakat mesti mampu menjalin kerjasama yang berkelanjutan dengan media massa. Sehingga tidak ada lagi jarak antara pengumpul zakat dengan masyarakat.

\section{Kesimpulan}

Berdasarkan dari tujuan penelitian dan data yang diperoleh di lapangan, maka dapat diperoleh kesimpulan sebagai berikut:

Dengan mempertimbangkan jumlah penduduk Jember 2,3 juta lebih dan mayoritas beragama Islam maka ada peluang untuk meningkatkan potensi jumlah muzaki dan dana ZIS yang dikumpulkan oleh tujuh (7) organisasi pengelola zakat masih bisa ditingkatkan untuk tahun-tahun yang akan datang. Dengan mempertimbangkan potensi jumlah muzaki dan jumlah dana ZIS yang dikumpulkan oleh tujuh (7) organisasi pengelola zakat yang mempengaruhi secara langsung jumlah dana ZIS yang disalurkan kepada mustahiq yang semakin bertambah maka potensi jumlah dana yang dapat disalurkan kepada para mustahiq di tahun-tahun mendatang. Dengan semakin besar potensi jumlah dana yang disalurkan kepada para musathiq maka ada peluang bagi ZIS untuk mampu mengentaskan penduduk miskin di Kabupaten Jember.

Hasil penelitian menyimpulkan bahwa manfaat dari penyaluran zakat, infak dan sedekah bagi mustahiq sebagai 
berikut; a) pemberian ZIS dapat menumbuhkan usaha mustahiq; b) pemberian ZIS dapat membantu sektor keuangan mustahiq; c) pemberian ZIS bisa membantu memulihkan kondisi ekonomi mustahiq; d) pemberian ZIS dapat mendorong keluarga miskin untuk berusaha mandiri agar dapat keluar dari garis kemiskinan; e) pemberian ZIS bermanfaat untuk menolong, membantu dan membina anda agar mendapat kehidupan lebih baik; f) pemberian ZIS merupakan sumber dana yang potensial bagi anda untuk meningkatkan kesejahteraan keluarga; g) ZIS ini produktif dan dilaksanakan melalui kegiatan ekonomi dimana mustahiq berperan sebagai pemilik usaha dan mengelolah usahanya sendiri; h) dana ZIS digunakan untuk pelatihan para mustahiq agar memiliki keahlian dan bisa mandiri secara ekonomi; i) penyaluran ZIS bisa mengurangi jumlah anak jalanan; j) ZIS dapat meningkatkan kesejahteraan kaum dhuafa secara materiil maupun spirituil; k) ZIS menumbuhkan jiwa kewirausahaan yang memiliki daya tahan/saing; 1) ZIS menimbulkan rasa kemanusiaan tinggi, menghilangkan sifat kikir, rakus dan materialistis; m) ZIS menumbuhkan ketenangan hidup, sekaligus membersihkan dan mengembangkan harta yang dimiliki; n) ZIS menjadikan mustahiq mengikuti orang-orang yang dermawan yang memiliki kebaikan dan kemurahan hati;

\section{Daftar Pustaka}

Abbas, Afifi Fauzi. 2011. Zakat Untuk Kesejahteraan Bersama. LAZISMU Situbondo.

Abdullah, Taufik. 1991. Zakat Collection and Distribution in Indonesia. The Islamic Voluntary Sector in Southeast Asia. Singapore: Institute of Southeast Asian Studies.Pages: 21-29

Clark, J. 1991. Democratizing Development: The Role of Voluntary Organizations. West Hartford, CT: Kumarian Press.

Cutt, J. and Murray, V. 2000. Accountability and Effectiveness Evaluation in Non-Profit Organizations, London: Routledge.

Dompet Dhuafa. 2011. Mengukur Kualitas Manajemen Zakat Di Indonesia: Irsindonesia.multiply.com.

Fox, J. dan L.D. Brown .1998. The Struggle for Accountability: NGOs, Social Movements, and the World Bank. Cambridge, 
MA: MIT Press.

Ibrahim, Anwar. 1998. Renaisans Asia: Gelombang Reformasi Di Ambang Alaf Baru. Mizan.

Ikatan Akuntan Indonesia (IAI). 2009. Standar Akuntansi Keuangan. Jakarta. Salemba Empat.

Ismail, Husin. 2009. Pola Pengumpulan, Distribusi Dan Pendayagunaaan Zakat.

Jones, Rowan, dan Maurice Pendlabury. 1994. Public Sector Accounting. $4^{\text {th }}$ edition. Pitman Publishing.

Mardiasmo. 2000. Value For Money Audit Dalam Pemeriksaan Keuangan Daerah Sebagai Upaya Memperkuat Akuntabilitas Publik. Makalah.

Mau'udi, Masdar F. 1991. Agama Keadilan: Risalab Zakat (Pajak) dalam Islam. Pustaka Firdaus: Jakarta.

Mila, Sartika. 2008. Pengarub Pendayagunaan Zakat Produktif terhadap Pemberdayaan.

Multifiah. 2009. "Pengaruh Zakat, Infak, Sedekah (ZIS) terhadap Kesejahteraan Rumah Tangga Miskin”. Jurnal-Jurnal ilmu Sosial. Fakultas Ekonomi Universitas Brawijaya Malang.

Riadi, Muslich. 2012. Teori Akuntabilitas. http://www.kajianpustaka. $\mathrm{com} /$

Megawat, Devi. 2012. Akuntanbilitas Pengelolaan Bantuan Kemanusian Di Indonesia BAZ Kota Pekanbaru.

Najam, A. 1996. NGO Accountability: A Conceptual Framework. Development Policy Review.

Nugraha, Winoto. 2011. Pengarub Dana Zakat Produktif Terhadap Keuntungan Usaha Mustabiq Penerima Zakat (Studi Kasus BAZ Kota Semarang) Fakultas Ekonomi Universitas Diponegoro Semarang.

Paul, S. 1992. Accountability in Public Services: Exit, Voice and Control. World Development.

Qardhawi, Yusuf. 1995. Kiat Islam Mengentaskan Kemiskinan. Gema Insani Press: Jakarta.

Rahmat Blog:blog.re.or.id (diakses Tanggal 24 Mei 2012).

Triyuwono, Iwan dan Roekhudin. 1999. Konsistensi Praktik Sistem 
Pengendalian Intern dan Akuntabilitas Pada Lazis, Studi Kasus di Laziz X Jakarta. Proceeding SNA II. Malang.

Triyuwono, Iwan. 1996. Shari'ate Organisation and Accounting: The Reflection of Self's Faith and Knowledge. Phd Dissertation. University of Wollonggong. Australia.

Undang-Undang Republik Indonesia nomor 23 Tahun 2011 tentang:

Pengelolaan Zakat. www.hukumonline.com/pusatdata/ download/.../parent/lt4eef02703-17fd Cache. Diakses Tanggal 20 Februari 2012.

Vatih, Ibrahim. 2010. Organisasi Pengelola Zakat Dituntut Transparan.IMZ.htm 